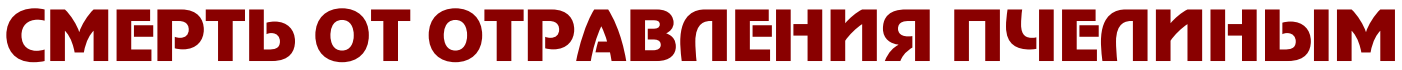 ЯดOM В PEЗУПЬTATE MHOKECTBEHHНIX УЖАПEHИЙ ПРИ HARИपИИ ЧЕРЕПНО-МОЗГОВОЙ ТРАВМЫ
}

И.М. Карлин, О.В. Карлина

Бюро судебно-медицинской экспертизы Московской области (нач. - д.м.Н., проф. В.А. Клевно), Москва

Аннотация: Проведена экспертная оценка случая наступления смерти в результате множественных ужалений пчелами при наличии тяжелой черепно-мозговой травмы давностью около 3-4 суток с переломом костей черепа и ушибом головного мозга, которая не вызвала смертельных осложнений и, следовательно, оценена, как сопутствующее повреждение.

Ключевые слова: множественные ужаления пчелами, апитоксин, черепно-мозговая травма

\section{DEATH FROM BEE'S VENOM POISONING AS A RESULT OF MULTIPLY BEE'S STING WITH PRESENCE OF SEVERE CRANIOCEREBRAL TRAUMA}

I.M. Karlin, O.V. Karlina

Abstract: This article deals with forensic evaluation of lethal case as a result of multiple bees' stings. Presence of severe craniocerebral trauma with skull's fracture and cerebral contusion, which duration was about 3-4 days, don't lead to deadly complications and was evaluated as concomitant disease.

Keywords: Multiple bee's stings, apitoxin, craniocerebral trauma

В судебно-медицинской экспертной практике нередко встречаются случаи наступления смерти в результате укусов перепончатокрылыми насекомыми, как правило, ужалений пчелами или осами. В подавляющем большинстве случаев смерть наступает после одного или нескольких ужалений в результате развития аллергических реакций немедленного типа в виде отека Квинке либо анафилактического шока. Случаи смерти от отравления пчелиным ядом в результате множественных ужалений крайне редки и лишь единичные описаны в доступной литературе [1]. Пчелиный яд - апитоксин (от греческого слова «аріх» - пчела и «toxikon» - яд) представляет собой бесцветную прозрачную коллоидную жидкость с характерным запахом, напоминающим запах меда, и горьким жгучим вкусом. Реакция яда кислая, удельный вес 1,131. Сухих веществ в пчелином яде $41 \%$. Химический состав пчелиного яда весьма сложен и окончательно не изучен, пчелиный яд представляет собой сложный комплекс жироподобных, минеральных веществ, аминокислот и белков. Белковый комплекс пчелиного яда делят на три основные фракции: нулевая, фракция 1 и фракция 2. Белки нулевой фракции лишены ядовитого действия и являются балластными веществами пчелиного яда [2].

Фракция 1 пчелиного яда обладает токсическим действием и представляет собой устойчивый к высокой температуре белок с молекулярным весом 35 000, названный мелитином. Мелитин считается основным действующим началом пчелиного яда. Большинство изменений, наступающих в организме при ужалении, обусловлены действием мелитина на нервную систему, мышцы, кровь и кровообращение. При соприкосновении с кровью мелитин вызывает гемолиз (распад эритроцитов). Мелитин расширяет кровеносные сосуды. Кроме того мелитин обладает и местным раздражающим действием, приводя к развитию воспалительной

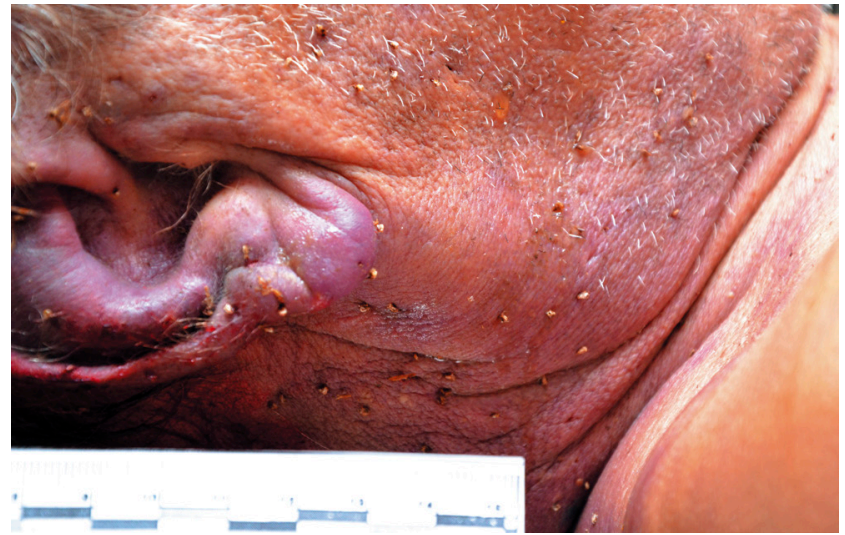

Рис. 1. Места ужалений на лице

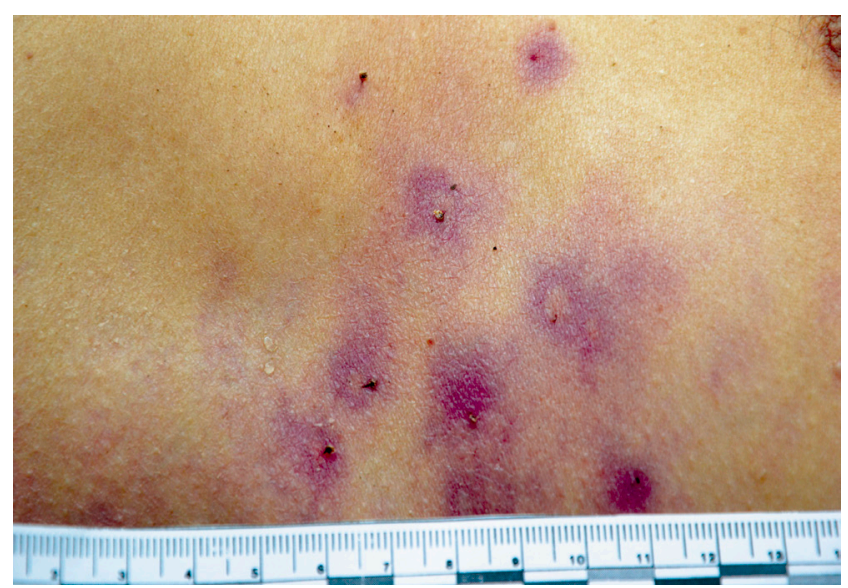

Рис. 2. Места ужалений на туловище 


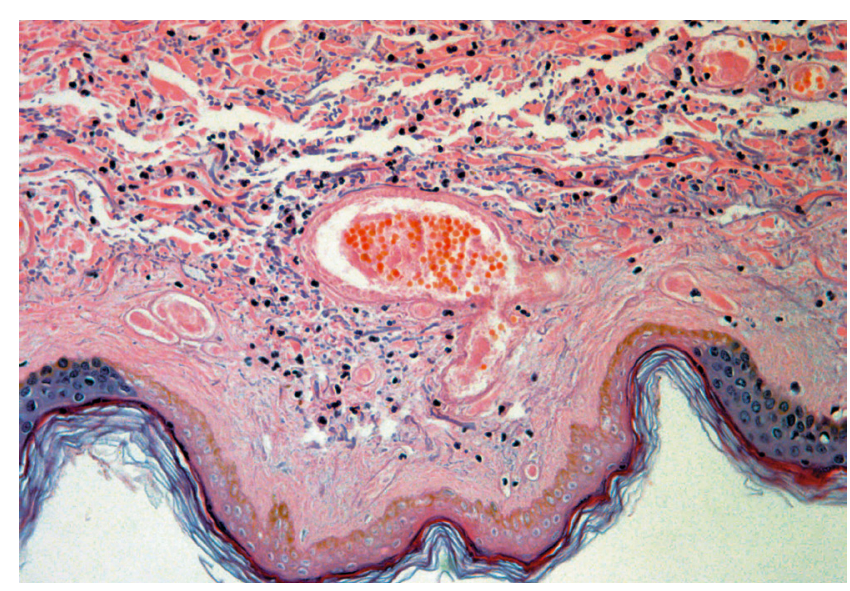

Рис. 3. Место ужаления - некроз эпителия. Окр. гематоксилином и эозином. Ув. 400

реакции на месте введения. Мелитин устойчив к действию кислот, щелочей, высоких и низких температур. Из фракции 1 выделено 13 аминокислот: аланин, глицин, лейцин, изолейцин, триптофан, аргинин, глютаминовая кислота, аспарагиновая кислота и др. Фракция 2 сравнительно малотоксична при внутривенном введении; в ее состав входят 18 аминокислот, 13 из которых аналогичны кислотам фракции 1 , а пять - аминокислоты: метионин, гистидин, фенилаланин, тирозин, цистин. Кроме того из фракции 2 выделены два весьма активных фермента: фосфолипаза А и гиалуронидаза. Первый расщепляет лецитин, входящий в состав оболочек клеток, что может приводить к повреждению клеток, вплоть до полного их распада. Воздействуя на эритроциты, фосфолипаза (лецитиназа) вызывает их гемолиз. Второй фермент фракции 2 - гиалуронидаза повышает проницаемость кровеносных сосудов, обусловливая быстроту всасывания яда при ужалении пчелами и усиливая местное действие яда. Фракция 2 угнетает один из ферментов, необходимых для свертывания крови - тромбокиназу, в результате чего снижается свертываемость крови. Поэтому в больших дозах пчелиный яд вызывает геморрагии (кровоизлияния) во внутренние органы.

При ужалении пчелами или осами развиваются местные и общие реакции на укус. Местно возникают гиперемия, отек, некроз тканей. Общая гиперергическая (аллергическая) реакция организма может проявляться следующими формами: 1 - кожная, или кожно-суставная (к примеру, по типу крапивницы); 2 - циркуляторная (анафилактический шок); 3 - отечно-асфиктическая (отек Квинке, отек гортани); 4 бронхоспастическая, или астматическая и 5 -смешанная $[1,3]$.

Смертельная доза пчелиного яда составляет не менее 0,2 г, что по данным разных авторов, составляет от 20 до 1000 одновременных ужалений, так как большое значение имеет индивидуальная чувствительность организма к пчелиному яду.

В нашей практике встретился случай смерти мужчины 58 лет. Труп обнаружен в дачном доме на кровати. Труп на месте обнаружения был осмотрен участковым уполномоченным полиции без участия судебно-медицинского эксперта. В протоколе осмотра места происшествия отмечено: «...В верхней части груди имеются множественные пятна красного цвета, напоминающие укусы пчел, ноги вытянуты... На лбу имеется рана 5 см длиной, покрытая корочкой коричневого цвета, в ране имеются следы вещества белого цвета, возможно лечеб-

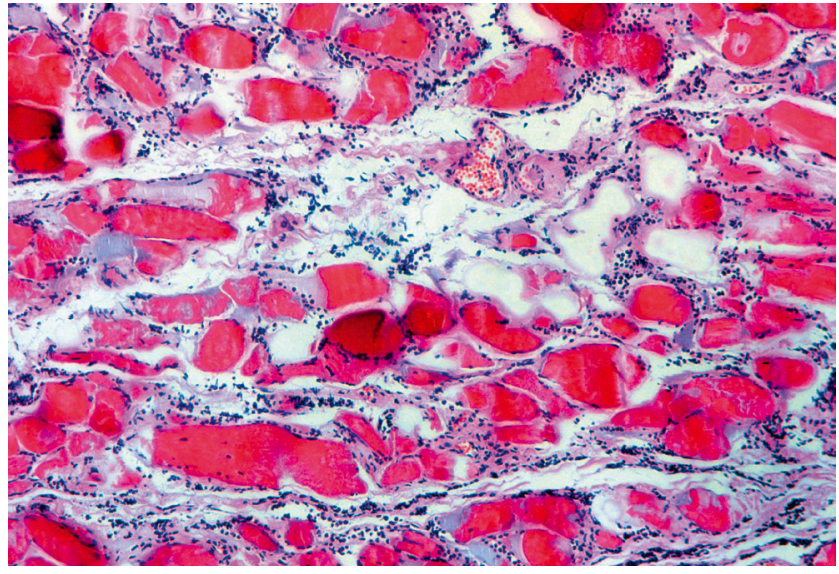

Рис. 4. Некроз мышечных волокон в дерме с лейкоцитарной реакцией. Окр. гематоксилином и эозином. Ув. 400

ной мази. Рана прикрыта двумя бумажными салфетками...». На территории дачи была пасека. Один из ульев перевернут, трава вокруг примята.

При наружном исследовании трупа на волосистой части головы, на лице, в области щек, подбородка, в области ушных раковин, за ушными раковинами, на шее по боковым, задней и передней поверхностям, в области надплечий, на грудной клетке в верхней части по передней поверхности, по боковым поверхностям, на животе, на верхних конечностях в области плеч, предплечий, в области кистей рук на тыльных и ладонных поверхностях, а также на спине было обнаружено более двухсот пятидесяти участков, где из кожи выстояли серого цвета инородные тела, состоящие из игольчатой и верхней расширенной части, общей длиной около $0,2 \mathrm{~cm}$ - жала пчел (рис. 1). В основном на грудной клетке вокруг этих инородных тел округлые участки диаметром $0,3-1,3 \mathrm{~cm}$ сине-фиолетовой окраски, напоминающие по виду кровоподтеки (рис. 2). На лбу слева имелась наклейка из двух полос сероватого цвета лейкопластыря. Под лейкопластырем кожа была обработана белой мазью и бриллиантовой зеленью. После удаления мази на коже обнаружены ушибленные раны с признаками заживления в краях. Судя по морфологическим особенностям ран, направление травматического воздействия было спереди назад и слева направо. Кроме того имелись ссадины на спинке носа и в левой скуловой области и кровоподтек на веках левого глаза. Все повреждения на лице, судя по их морфологическим особенностям, имели давность не менее нескольких суток.

При внутреннем исследовании установлено жидкое состояние крови и острое венозное полнокровие внутренних органов. Обратил на себя внимание тот факт, что имел место гемолиз крови с незначительным красноватым прокрашиванием интимы крупных сосудов, при отсутствии гнилостных изменений мягких тканей и внутренних органов и давности наступления смерти около суток. Отека слизистой оболочки голосовых складок и сужения голосовой щели не установлено. Была установлена черепно-мозговая травма с кровоизлиянием в мягкие ткани лба слева, соответственно ушибленным ранам, линейным переломом костей свода и основания черепа, наличием ушиба полюса левой лобной доли по наружной его поверхности и ушиба задних отделов правой височной доли по типу противоударного очага. Кровоизлияния в мягкие ткани были «суховатые», с желтоватым оттенком. Признаков отека и дислокации головного мозга не установлено. Был направлен соответствующий материал на судебно-гистологическое, судебно-химическое и судебно-био- 


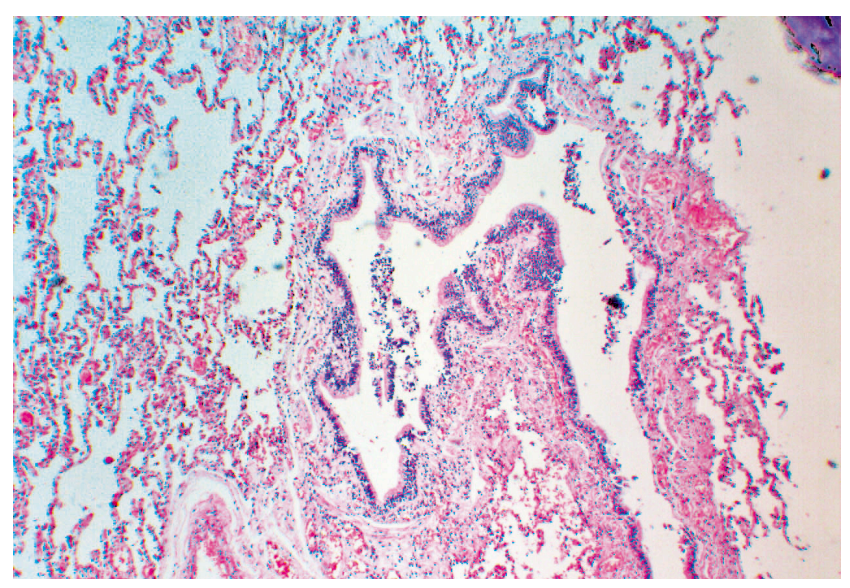

Рис. 5. Разрешающийся бронхоспазм с лейкоцитарной реакцией. Окр. гематоксилином и эозином. Ув. 200

химическое исследования. После исследования трупа запрошены материалы расследования. Из представленных материалов расследования установлено, что за три и за один день до наступления смерти погибшего встречали соседи по улице, разговаривали с ним, видели у него повязку на лбу. Погибший рассказывал им, что он упал на дачном участке.

При судебно-гистологическом исследовании в месте ужаления обнаружены очаги некроза в эпидермисе, дерме, подкожной жировой клетчатке, подлежащей мышечной ткани с выраженной лейкоцитарной реакцией и небольшое очаговое кровоизлияние в подкожной жировой клетчатке без резорбции (рис. 3, 4). В кусочках из мягких тканей лобной области, в очагах ушиба головного мозга обнаружены признаки резорбции в виде наличия единичных гемосидерофагов со светло окрашенной цитоплазмой, которые обычно начинают определяться на 3-4 сутки. Таким образом, с учетом макроскопической и микроскопической картины, давность черепно-мозговой травмы составила примерно 3-4 суток, что подтверждалось предоставленными материалами расследования. В легких выявлен разрешающийся бронхоспазм с лейкоцитарной инфильтрацией стенок бронхов, с признаками гиперсекреции эпителия бронхов, наличием слизи в просвете бронхов (рис. 5,6 ). Установлены дистрофические изменения в паренхиматозных органах.

При судебно-химическом исследовании в крови, моче и внутренних органах от трупа обнаружены анальгин и димедрол. При судебно-биохимическом исследовании обнаружено резкое снижение в печени и скелетной мышце гликогена. Обнаруженная черепномозговая травма отнесена нами в рубрику сопутствующих повреждений, так как не вызвала выраженного отека головного мозга и его дислокации.

Черепно-мозговая травма была причинена воздействием массивного твердого тупого предмета с преобладающей контактирующей поверхностью по левой половине лица - области лба, левой скуловой области

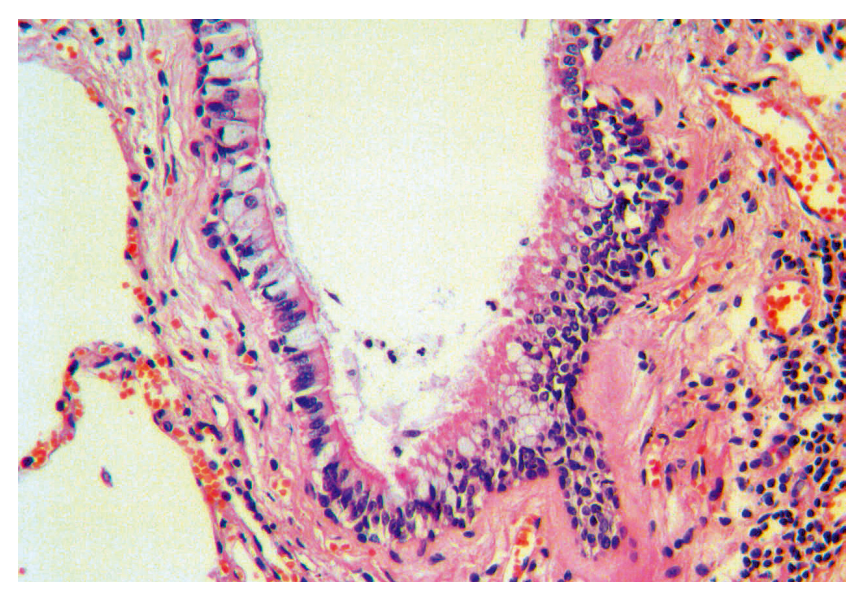

Рис. 6. Повышенная секреция эпителия бронхов. Окр. гематоксилином и эозином. Ув. 400

и спинки носа с преимущественным направлением воздействия спереди назад и слева направо. Морфологические особенности черепно-мозговой травмы (место приложения силы на лице слева, наличие очагов ушиба в месте первичного воздействия - на полюсе левой лобной доли головного мозга и на противоположной стороне - на боковой поверхности правой височной доли головного мозга, линейный характер перелома костей черепа в проекции повреждений на коже лобной области слева) позволили высказаться о том, что черепно-мозговая травма образовалась по инерционному механизму и могла быть получена при падении потерпевшего из вертикального или близкого к нему положения с последующим ударом левой половиной лица о плоскость, а наличие относительно большого количества повреждений на небольшой площади могло свидетельствовать о неровной поверхности травмирующего предмета.

Таким образом, на наш взгляд, имел место редкий случай наступления смерти в результате множественных ужалений пчелами при наличии тяжелой черепномозговой травмы с переломом костей черепа и ушибом головного мозга.

Вышеизложенные данные позволили нам сделать вывод, что смерть мужчины наступила от острого отравления пчелиным ядом в результате множественных ужалений пчелами.

\section{ЛИТЕРАТУРА}

1. Сабалдаш А.И. Смерть от ужаления пчелами // Судебно-медицинская экспертиза. - 1958. - № 3. - С. 51-53.

2. Интернет-ресурс http://pudmeda.com/article/ Himicheskij_sostav_pchelinogo_jada

3. Справочник по оказанию скорой и неотложной помощи / сост. О.М. Елисеев. СПб.: Лейла, 1996. - 672 с.

4. Северова Е.Я., Велишева Л.С. Вопросы приобретенной аллергии в судебно-медицинской практике. - М.: Медицина, 1972. - 160 с.

\section{Для корреспонденции:}

КАРЛИН Игорь Маркович - заведующий танатологическим отделом, врач - судебно-медицинский эксперт государственного бюджетного учреждения здравоохранения Московской области «Бюро судебно-медицинской экспертизы» (ГБУЗ МО «Бюро СМЭ»). Адрес: 111401, г. Москва, ул. 1-я Владимирская, д. 33, корп. 1, ГБУ3 МО «Бюро CMЭ»•E-mail: karlin@sudmedmo.ru

КАРЛИНА Ольга Владимировна - заведующая судебно-гистологическим отделением, врач - судебно-медицинский эксперт государственного бюджетного учреждения здравоохранения Московской области «Бюро судебномедицинской экспертизы» (ГБУЗ МО «Бюро СМЭ»). Адрес: 111401, г. Москва, ул. 1-я Владимирская, д. 33, корп. 1, ГБУЗ МО «Бюро СМЭ»• E-mail: karlina@sudmedmo.ru 